\title{
DA PRODUÇÃO À SOBREVIVÊNCIA: A IMPORTÂNCIA DA ESTRATÉGIA NA CRIAÇÃO DE VALOR*
}

\author{
Maria Isolina Dinis Poeta**
}

As pesquisas levadas a cabo desde os anos 40 no campo da estratégia empresarial permitiram desenvolver conceitos $e$ ferramentas que constituem, hoje, o corpo de uma nova disciplina: $A$ gestão estratégica da empresa. Trata-se de uma disciplina autónoma que, desde há alguns anos, integra a estrutura curricular dos cursos vocacionados para formar futuros dirigentes de empresas.

A aplicação e o conhecimento actual sobre a teoria da gestão estratégica, tendo em vista evitar erros e orientar os dirigentes, permitem, hoje, formalizar os conceitos e fornecer um conjunto de soluções possíveis, indicando os factores-chave de sucesso que, em cada caso, se podem apresentar.

$O$ "porquê" da reflexão estratégica conduzirá, inevitavelmente, à análise da cadeia de valor, permitindo identificar o posicionamento da empresa e as suas vantagens competitivas, que mais contribuem para a criação de valor, de forma a assegurar a sua sobrevivência a longo prazo.

A reflexão estratégica coloca a questão "o quê?", isto é, quais as questões-chave a que os decisores deverão dar resposta. Estas devem ser equacionadas a dois níveis: ao nível da empresa, como um todo, e ao nível da unidade estratégica de negócio.

Por último, dado que uma das componentes importantes da estratégia se relaciona com o processo de decisão, a nossa

** Professora Associada da Universidade de Trás-os-Montes e Alto Douro. 


\begin{abstract}
abordagem tem por objectivo sugerir algumas normas de conduta que devem ser consideradas na definição do "quem", "onde" e "como". Assim, procedemos a uma descrição genérica da alguns métodos de diagnóstico e formulação da estratégia, nomeadamente as leis universais de sucesso e os métodos de resolução dos problemas estratégicos.
\end{abstract}

Palavras-chave: Gestão estratégica, cadeia de valor, vantagem competitiva, processo estratégico.

\title{
1. O CONCEITO DE ESTRATÉGICA
}

Sobrevivência a longo prazo: eis a questão!

Quando nos situamos ao nível da gestão de topo das empresas, dois aspectos podem ser referenciados (HAFER e SCHENDEL, 1978): por um lado, a atenção dada pelos dirigentes quanto à sobrevivência a longo prazo e, por outro, a estratégia como medida associada a tal sobrevivência.

De facto, algumas empresas conseguem sobreviver a longo prazo e outras não; a questão consequente é: o que faz "algumas sobreviverem e outras não"? (GLUEC, 1980) atribui tal facto "à gestão estratégica adequada". Ora, o que seria uma gestão estratégica adequada? Acredita-se, por raciocínio lógico, que seja o processo de decisão estratégica ou o comportamento estratégico da empresa que consegue assegurar a sobrevivência a longo prazo, visto que a estratégia é um conceito associado a tal sobrevivência.

Como refere FREIRE (1997): "Todas as empresas ambicionam alcançar o sucesso, na forma de maiores vendas, resultados acrescidos ou cotações bolsistas mais elevadas. Para esse efeito, procuram adoptar estratégias que proporcionem aos seus clientes mais valor que a concorrência, aproveitando todas as potencialidades dos recursos à sua disposição. O desempenho competitivo a longo prazo depende por isso da correcta formulação e implementação das suas orientações estratégicas (...). O sucesso empresarial é reconhecido pela sobrevivência a longo prazo da organização, pelo crescimento sustentado das suas vendas, pela obtenção de uma rentabilidade adequada e pela demonstração de uma sólida capacidade de inovação".

A palavra estratégia teve origem na palavra grega strategos, significando, em sentido estrito, um general no comando de um exército 
- stratos, exército e ag, comandar (EVERED, 1983). Primordialmente, o termo está associado à área militar.

Mais precisamente, ao falar de estratégia, entendem-se as decisões e orientações relativas aos objectivos (crescimento, diferenciação, rentabilidade, mais valia social), às actividades a promover, aos investimentos a realizar (pesquisa e desenvolvimento, marketing, capacidade produtiva, ...), ao posicionamento face a outros actores no sistema concorrencial (conflitos, mentalidade, alianças, aquisições, ...); em suma, um conjunto de escolhas importantes para o sucesso da empresa, para a sua adaptação à evolução do meio envolvente e sua influência sobre ele e definitivamente para a sua sobrevivência.

Nesta exposição, optamos por apresentar um conjunto ordenado de métodos que permitam fazer um diagnóstico geral e formular uma estratégia, quer para o conjunto da empresa, quer para uma unidade estratégica de negócio. Os métodos propostos foram seleccionados e ordenados, tendo em conta a coerência do conjunto das várias componentes, mas que não ignora a importância da intuição, inovação e flexibilidade em todo o processo de mudança.

\section{REFLEXÃO ESTRATÉGICA: PORQUÊ?}

\subsection{Criação de valor, vantagem competitiva}

Os sistemas de planeamento implementados na maioria das grandes empresas nos anos sessenta e setenta, coordenados pelos departamentos de planeamento, foram, a maior parte das vezes, percebidos pelos operacionais (directores de filiais, de departamentos ou de centros de custo) como iniciativas auto-suficientes ao serviço da direç̧ão geral. Noutros termos, porquê fazer planeamento estratégico? "Para elaborar um plano"...; "para produzir mais papelada" ...; "para ensaiar previsões"...; "uma outra forma de controlo".

Se os planos de médio/longo prazo descansam, muitas vezes, nas gavetas, é porque nem sempre respondem a uma necessidade de reflexão percebida, a fim de dar um sentido à acção.

Uma reflexão estratégica justifica-se enquanto permite reforçar a consciência das pessoas face às metas a atingir e à coerência dos actos para criar valor para os clientes, trabalhadores (que contribuem com o seu trabalho), os accionistas (que contribuem com o seu capital) e, mais genericamente, a comunidade. A finalidade da criação de valor é comum 
a todas as empresas. Em sistema concorrencial falar-se-á em criação de uma vantagem competitiva (valor superior ao dos concorrentes) ou factor chave de sucesso; em situação de monopólio (certos serviços públicos, por exemplo) falar-se-á simplesmente em criação de valor. Em sistema concorrencial falamos de "clientela-alvo" para quem se cria este valor; em situação de serviço público falamos de "prioridade", porque, por definição, o serviço público serve sem discriminação o conjunto de comunidade.

\subsubsection{As fontes de valor ou fontes de vantagem competitiva}

A produção-consumo de um bem ou de um serviço exprime-se por um certo nível de qualidade (em sentido lato, satisfação do cliente consumidor), um certo nível de custos. O preço resulta dos dois primeiros parâmetros e das forças competitivas.

Figura 1

FONTES DE VANTAGENS COMPETITIVAS OU DE VALOR

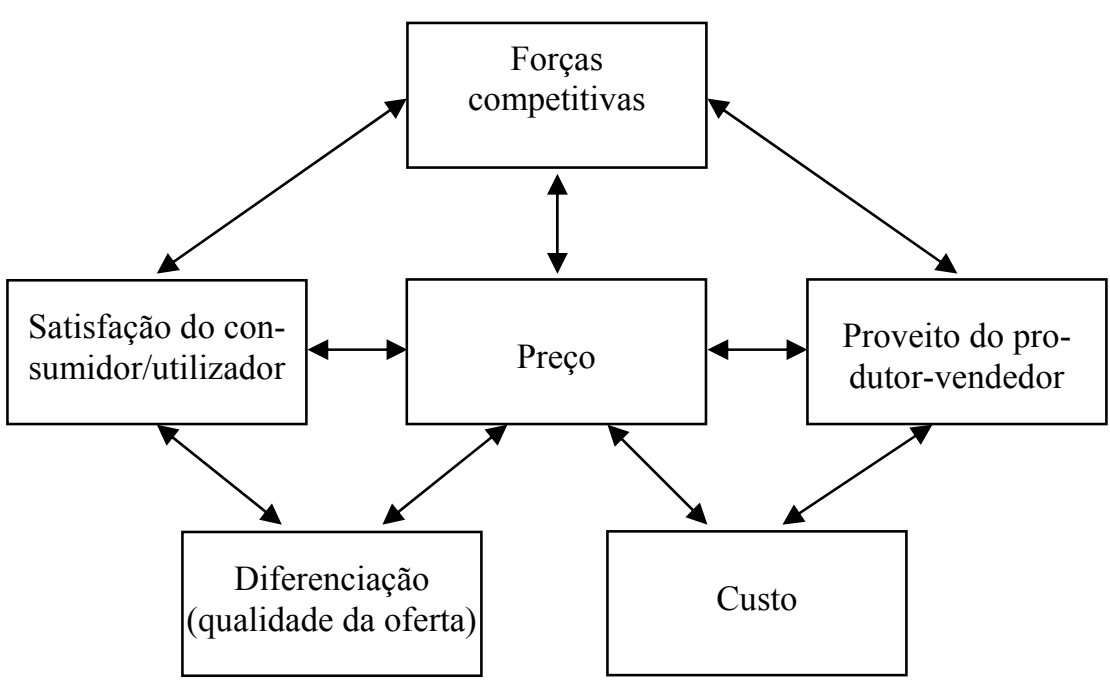

Fonte: Adaptado de Porter (1985). 
As duas fontes de valor são a qualidade (dos produtos, serviços e imagem) e o custo, em comparação com a qualidade e custo dos concorrentes. Em ambiente competitivo, fala-se de "diferenciação", qualidade diferenciada e superior à dos concorrentes, de acordo com numerosos autores, entres eles Porter. O termo "diferenciação (definido como a originalidade percebida pelos clientes), apesar de limitado a um universo concorrencial, será preferível ao conceito de qualidade que é muitas vezes empregue num sentido restrito de "qualidade do produto ou serviço".

$\mathrm{Na}$ prática, para orientar a procura de fontes de vantagens competitivas numa determinada actividade, utilizam-se três métodos extremamente simples: a análise das fontes de valor para os clientes, a análise da cadeira vertical de concepção - produção - distribuição dos bens ou serviços (ou cadeia de valor, segundo M. Porter) e a análise das componentes da diferenciação e das componentes dos custos.

\subsubsection{A análise das fontes de valor para os clientes}

Trata-se de identificar os elementos da oferta que têm um valor para os clientes. O termo cliente abrange quer os compradores, quer os utilizadores, distribuidores e eventuais prescritores.

$\mathrm{O}$ valor para um cliente pode exprimir-se em termos de qualidade (percebida) do produto ou serviço, prazo de entrega, qualidade de produtos e serviços relacionados, condições de pagamento, serviço pósvenda ou preço. Os estudos sobre o comportamento de compra têm por objectivo identificar estas fontes de valor percebidas pelos clientes.

Especialistas ou líderes de opinião podem também substituir-se aos clientes para expressar a sua percepção dos elementos constitutivos do valor para os clientes (como é o caso de alguma comunicação publicitária). Por exemplo, podemos formular a seguinte questão: quais são, por ordem de importância, as cinco características da oferta que têm um valor para os clientes? A Figura 2 propõe uma referência para esta análise.

Esta abordagem "extrovertida", típica de uma pesquisa de marketing, é complementar de uma análise da oferta segundo a cadeia de valor vertical. 
Figura 2

GRELHA PARA A ANÁLISE DAS FONTES DE VALOR

PARA OS CLIENTES

Estudo do comportamento dos

Clientes

e/ou

Consulta de Especialistas

e/ou

Líderes de opinião

\begin{tabular}{|c|}
\hline $\begin{array}{l}\text { Elementos da oferta que têm } \\
\text { valor para os clientes }\end{array}$ \\
\hline 1 \\
\hline 2 \\
\hline 3 \\
\hline 4 \\
\hline 5 \\
\hline
\end{tabular}

Fonte: Elaborado pela autora

\subsubsection{Análise da cadeia de valor vertical}

É um quadro de referência que permite decompor as diferentes etapas do processo de concepção - produção - distribuição, desde a concepção do produto ou serviço até ao seu consumo final.

Este quadro de referência, inspirando-se no posicionamento ocupado pela empresa na cadeia de valor, exige a identificação "à priori" dos vários elos da cadeia. A Figura 3 representa um exemplo simplificado da decomposição da cadeia de valor da indústria de caixas de cartão. 
Figura 3

EXEMPLO SIMPLIFICADO DA CADEIA DE VALOR VERTICAL

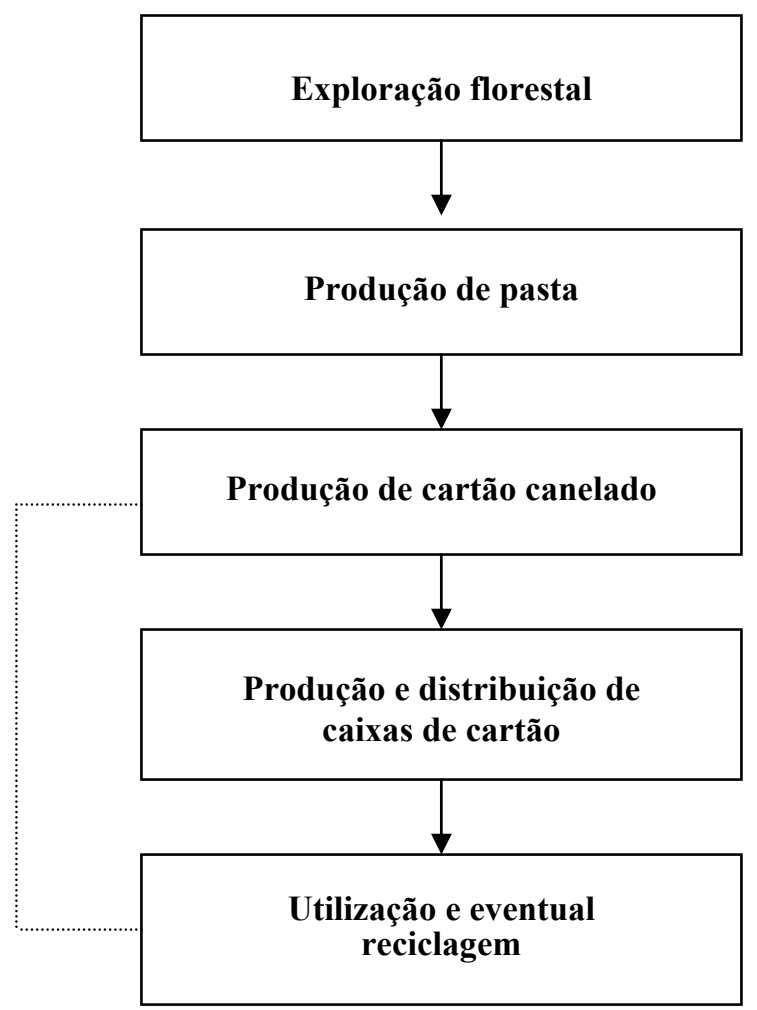

Uma segunda análise consiste em decompor mais detalhadamente cada um dos elos da cadeia, em actividades ou funções mais precisas. $\mathrm{Na}$ Figura 4 apresenta-se uma grelha padronizada. 
Figura 4

GRELHA DE ANÁLISE DAS FONTES DE VANTAGENS COMPETITIVAS

\begin{tabular}{|c|c|c|c|c|}
\hline \multirow[t]{2}{*}{ Cadeia Vertical } & \multicolumn{2}{|c|}{$\begin{array}{c}\text { Fontes de Vantagem } \\
\text { Competitiva }\end{array}$} & \multicolumn{2}{|c|}{ Recursos } \\
\hline & $\begin{array}{l}\text { Diferenci- } \\
\text { ação }\end{array}$ & Custo & Humanos & $\begin{array}{l}\text { Finan- } \\
\text { ceiros }\end{array}$ \\
\hline \multirow{4}{*}{\multicolumn{5}{|c|}{$\begin{array}{l}\text { Concepção } \\
\text { Logística à entrada } \\
\text { Produção: operação } 1 \\
\text { Produção: operação } 2\end{array}$}} \\
\hline & & & & \\
\hline & & & & \\
\hline & & & & \\
\hline \multicolumn{5}{|l|}{ (..., } \\
\hline \multicolumn{5}{|l|}{ Produção: operação n } \\
\hline \multicolumn{5}{|l|}{ Logística à saída } \\
\hline \multicolumn{5}{|l|}{ Marketing e comercialização } \\
\hline \multicolumn{5}{|l|}{ Serviços } \\
\hline Capacidades de gestão & & & & \\
\hline
\end{tabular}

Fonte: Adaptado de Porter (1985).

Considerando cada uma das etapas do processo concepção - produção - distribuição de cada elo, a estratégia interroga-se sobre as possíveis fontes (actuais e potenciais) de criação de valor (ou vantagens competitivas). As colunas da esquerda da Figura 4 permitem identificar a natureza da vantagem competitiva possível: diferenciação e/ou custo. As colunas da direita indicam se esta vantagem de diferenciação e/ou custo requer recursos humanos e/ou financeiros significativos.

\subsubsection{Análise das componentes da diferenciação e dos custos}

Justifica-se distingir duas fontes principais de vantagens competitiva pela diferenciação e duas pelos custos.

$\mathrm{Na}$ origem de uma vantagem competitiva pela diferenciação podemos distingir duas tipologias de saber-fazer ou de activos: o saber-fazer (e activos) tecnológicos e o saber-fazer (e activos) marketing. Quanto à vantagem competitiva pelos custos podemos enunciar dois tipos de causas: o custo unitário dos factores de produção e a produtividade. Por 
custo unitário dos factores entende-se o custo unitário do trabalho (salários, encargos sociais, etc.) e o custo unitário do capital, agindo a pressão fiscal sobre os dois. Vários factores podem estar na origem de vantagens pela produtividade: a inovação do produto, a inovação de processos, o pleno emprego dos activos, os esforços de análise e controlo dos custos, a motivação do pessoal, os efeitos de escala e de experiência, os métodos e técnicas de gestão, apenas para citarmos os principais. A Figura 5 retrata estas distintas componentes da criação de valor. As capacidades de gestão estão na origem da criação de valor.

\section{Figura 5}

\section{FONTES DE CRIAÇÃO DE VALOR}

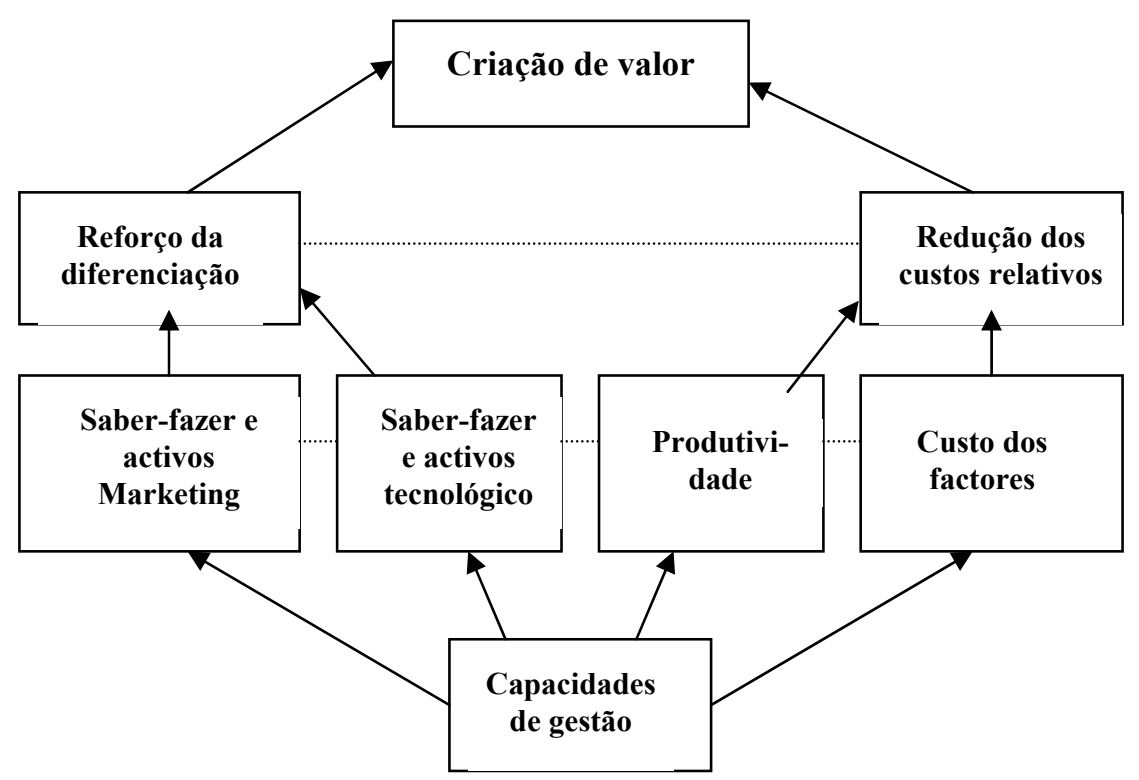

Fonte: Elaborado pela autora.

Como indicam os traços horizontais a picotado da Figura 5, existem interacções múltiplas e complexas entre a posição na diferenciação e a posição em custos, entre o saber-fazer marketing, tecnológico, a produtividade e o custo dos factores. 


\subsection{Criar valor para quem?}

A criação de valor destina-se a três tipos de actores: os clientes, o pessoal e os accionistas. Para além destes actores, directamente envolvidos, a comunidade como um todo é também um dos interessados, pelo menos pelo lado da pressão fiscal, das actividades induzidas e do equilíbrio ecológico.

Por fim, põe-se a questão da repartição do valor gerado entre os clientes, pessoal, accionistas e o resto da colectividade. Esta repartição tem por base a política de preços que pode aumentar o valor para os clientes (baixando os preços) ou aumentar as margens de lucro da empresa (aumentando os preços). Faz-se também tendo por base a repartição das margens de lucro, por vezes aumentando as remunerações salariais ou melhorando as condições de trabalho, outras vezes aumentando a remuneração do capital, quer sob a forma de autofinanciamento (mais-valias), quer sob a forma de dividendos.

O jogo da repartição do valor gerado pelos vários elos e actividades da cadeia de valor não é um jogo de resultado nulo, pois os comportamentos dos clientes, pessoal e accionistas influenciam o desempenho da empresa. Por outro lado, a lista de cada actor não é unívoca, alguns clientes e trabalhadores podem ser também accionistas; por vezes, os trabalhadores podem também ser clientes. Mas a questão da repartição do valor mantém-se, é uma das questões-chave na estratégia da empresa resumida na Figura 6.

Ter êxito na criação de uma comunidade de interesses, ou pelo menos a coerência de interesses, entre estes quatro grupos de actores interessados, é provavelmente o maior desafio das empresas. 
Figura 6

COMO REPARTIR O VALOR

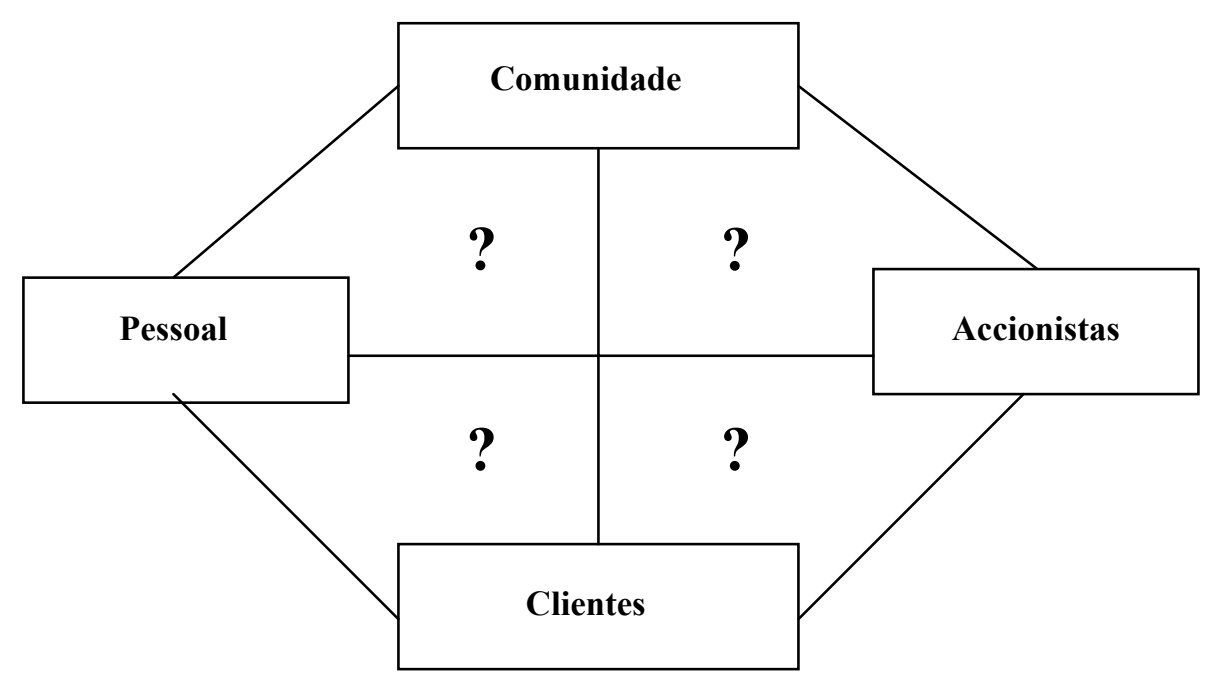

Fonte: Elaborado pela autora.

\section{REFLEXÃO ESTRATÉGICA: O QUÊ?}

Sobre este ponto, o nosso objectivo não é inventariar os modelos que descrevem as estratégias das empresas desde ANSOFF a PORTER, mas apresentar algumas normas de conduta que orientam a definição de estratégia. Para tal, distinguimos dois níveis de formulação da estratégia: o nível do conjunto da empresa e o nível de cada unidade estratégica de negócio.

\subsection{Estratégia de uma unidade estratégica de negócio}

Definiremos uma unidade estratégica de negócio, que é uma unidade elementar de formulação de uma estratégia, como um conjunto de actividades de uma empresa que têm factores-chave de sucesso semelhantes e que partilham recursos e capacidades. Se as regras do jogo concorrencial, ou factores-chave de sucesso, são praticamente os 
mesmos, então (por definição) pode formular-se uma estratégia específica para este negócio (diferente da estratégia noutras unidades estratégicas de negócio), coerente com a combinação específica de factores chaves de sucesso.

A Figura 7 integra as sete componentes de uma estratégia, ao nível de uma unidade estratégica de negócio.

Figura 7

COMPONENTES DA ESTRATÉGIA DE UMA

UNIDADE ESTRATÉGICA DE NEGÓCIO

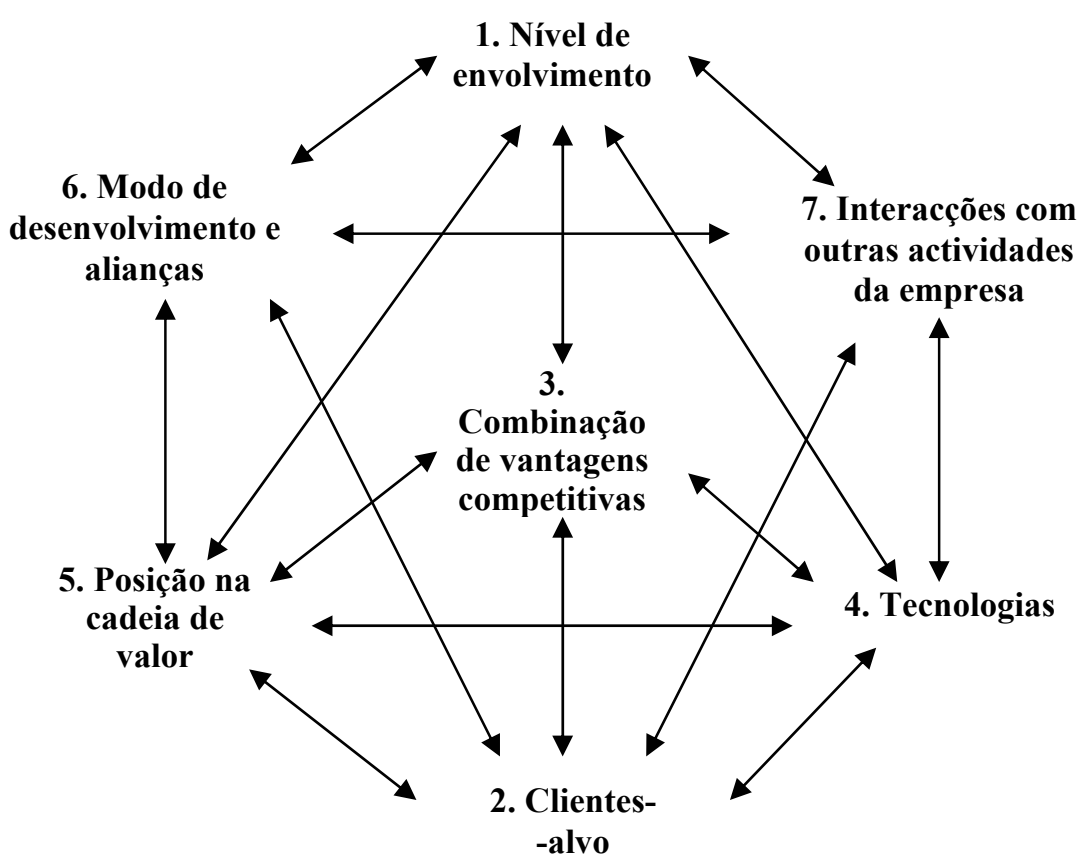

Fonte: Elaborado pela autora.

\subsubsection{Nível de envolvimento}

O nível de envolvimento de uma empresa numa determinada unidade estratégica de negócio (actual ou nova) pode ser expresso em termos qualitativos: "desenvolvimento prioritário, desenvolvimento, 
manutenção, selectividade (escolha de alguns segmentos ou clientes-alvo e abandono de outros), retracção selectiva, retracção ou abandono. De outra maneira, o nível de envolvimento pode ser expresso em termos financeiros: Rentabilidade, taxa de crescimento do volume de negócios, investimentos, recursos humanos.

\subsubsection{Clientes-alvo}

Ao nível de uma unidade estratégica de negócio, definir alvos traduz-se na escolha de certos segmentos e microssegmentos de clientes que a empresa define como prioritários e sobre os quais concentra os seus esforços comerciais, de marketing, financeiros e técnicos.

Uma unidade estratégica de negócio é composta por vários segmentos e um segmento de mercado compõe-se de vários microssegmentos. Trata-se de escolher os segmentos e microssegmentos-alvo em função da atraç̧ão de cada um e do posicionamento competitivo (actual ou potencial) da empresa em cada segmento ou microssegmento. A escolha de segmentos ou clientes-alvo torna-se determinante nas unidades em que o objectivo estratégico é a selectividade.

\subsubsection{Combinação de vantagens competitivas}

De entre todas as fontes de valor ou de vantagens competitivas, o decisor escolhe aquelas em que a empresa vai criar ou defender um posicionamento superior, aquelas em que a empresa tem uma posição semelhante à dos melhores concorrentes. Trata-se de escolher um conjunto de factores-chave de sucesso em relação aos quais a empresa se quer diferenciar. Este conjunto de factores pode ser mais ou menos inovador. Assenta, em parte, no diagnóstico do posicionamento competitivo da empresa e, em parte, na intuição dos estrategas que, por vezes, descobrem novas fontes de vantagens competitivas ou de novas combinações: estratégias inovadoras.

\subsubsection{Tecnologias}

As tecnologias escolhidas pela empresa no passado determinam e condicionam o posicionamento presente quanto aos factores-chave de 
sucesso. Da mesma maneira, as escolhas tecnológicas de hoje devem ser coerentes com as vantagens competitivas que se pretendem desenvolver na actividade.

A escolha de tecnologia é, a maior parte das vezes, dificilmente reversível. Neste sentido, tem um carácter tão estratégico como as escolhas de alvos e vantagens competitivas. Contudo, nas indústrias emergentes e nas fases de pesquisa e desenvolvimento, as escolhas estratégicas de tecnologias (produtos e processos) são feitas, muitas vezes, sem se ter uma ideia clara dos futuros alvos e vantagens competitivas.

Numa determinada unidade estratégica de negócio, existem geralmente várias possibilidades de escolha entre tecnologias concorrentes para satisfazer uma mesma família de aplicações e clientes. Deste modo, o primeiro problema centra-se na escolha da carteira de tecnologias, produto e processo que melhor desempenho permitem (eficácia e eficiência). Um outro problema consiste em escolher uma atitude face aos investimentos técnicos: inovadora ou imitadora; e o modo de acesso à tecnologia. $\mathrm{O}$ terceiro problema consiste em proteger $\mathrm{o}$ saber--fazer tecnológico e assegurar o seu desenvolvimento na empresa (um aspecto de desenvolvimento dos recursos humanos).

\subsubsection{Posicionamento na cadeia de valor}

Numa dada actividade, uma empresa tem de escolher entre integrar a maior parte das actividades da cadeia de valor vertical (concepção produção - comercialização) do bem ou serviço ou, pelo contrário, focalizar-se em determinadas operações (elos) da cadeia.

Com efeito, a integração vertical é um movimento importante que, normalmente, necessita de novas competências. Trata-se de escolher entre transacções internas (fazer) e transações externas (comprar). As decisões de subcontratação são decisões acerca do posicionamento na cadeia de valor. Estas decisões são muitas vezes fundamentais para assegurar a flexibilidade de uma empresa, bem como o pleno emprego dos activos. De facto, a escolha faz-se tendo em conta vários níveis de integração: integração completa, integração modular e alianças com empresas quer a montante quer a jusante.

A escolha do posicionamento na cadeia de valor vertical não tem sido muito tratada na literatura sobre estratégia, apesar da sua relevância na formulação estratégica. Formular híbridos de integração devia ser alvo de 
maior atenção, tais como: contratos a longo prazo com fornecedores e clientes, integração parcial ou quase-integração sob a forma de participações minoritárias, partilha de instalações logísticas especializadas, cooperação em pesquisa e desenvolvimento.

\subsubsection{Modo de desenvolvimento e alianças}

Desenvolvimento de capacidades, tecnologias, investimento em capital, quotas de mercado, reposicionamentos na cadeia de valor podem materializar-se tanto pelo desenvolvimento interno (orgânico), como pelo desenvolvimento externo (aquisições, fusões, participações, ...). Uma terceira fórmula, mista, combinando desenvolvimento interno e externo, assente em sociedades conjuntas (joint-ventures), acordos de colaboração e alianças, está, hoje em dia, a ser praticada, ou seja, o que podemos designar por desenvolvimento partilhado. As estratégias de alianças ultrapassam, contudo, o simples quadro de desenvolvimento, conduzindo ao reforço de uma rede de interrelações entre a empresa e outros actores económicos e sociais.

Conforme referem Atamer et al. (ATAMER, 1988), as alianças são um meio de mobilizar recursos suplementares do ambiente externo da empresa e justificam-se na medida em que reforçam uma vantagem competitiva e conduzem a uma redução do risco, pois os parceiros contribuem com forças complementares e recursos adicionais.

\subsubsection{Interaç̧ões com outras actividades da empresa}

As decisões referentes à interacção com outras actividades estão na fronteira entre a estratégia de uma unidade de negócio e a estratégia do conjunto da empresa. Na perspectiva da estratégia de uma unidade de negócio, trata-se de estabelecer eventuais ligações de recursos e capacidades com outras actividades da empresa. Estas decisões completam e precisam as decisões de estratégias horizontais e devem, assim, desenvolver-se num contexto de coerência com estas últimas, contemplando os seguintes aspectos: partilha de recursos, transferência de saber-fazer, efeito de economias gama e de imagem entre a actividade considerada e as outras.

A Figura 8, adaptada de Porter, apresenta as diversas fontes de interacções possíveis. 
Figura 8

FONTES POSSÍVEIS DE INTERACÇÕES

\begin{tabular}{|c|c|}
\hline Interacções de capital & Interacções de produção \\
\hline - Financiamento & - Logística interna comum \\
\hline - Utilização recíproca de Tesouraria & $\begin{array}{l}\text { - Fabrico comum de peças } \\
\text { - Sistema conjunto de controlo } \\
\text { de qualidade }\end{array}$ \\
\hline Interacções e infra-estrutura & - Infra-estruturas gerias comuns \\
\hline - Relações com os poderes públicos & - Transferência de saber-fazer \\
\hline - Serviços jurídicos comuns & de produção \\
\hline - Contabilidade comum & \\
\hline - Serviços de planificação/controlo comuns & $\begin{array}{l}\text { Interacções comerciais e } \\
\text { Marketing }\end{array}$ \\
\hline $\begin{array}{l}\text { - Desenvolvimento comum de recursos } \\
\text { humanos }\end{array}$ & $\begin{array}{l}\text { - Força de vendas conjuntas } \\
\text { - Logística de distribuição } \\
\text { comuns }\end{array}$ \\
\hline - Meios informáticos comuns & $\begin{array}{l}\text { - Rede de serviço pós-venda } \\
\text { comuns } \\
\text { - Venda em bloco } \\
\text { - Clientes comuns }\end{array}$ \\
\hline Interacções tecnológicas & - Marca comercial comum \\
\hline $\begin{array}{l}\text { (partilha de recursos e/ou transferência de } \\
\text { saber-fazer) }\end{array}$ & $\begin{array}{l}\text { - Serviço de estudos de mercado } \\
\text { comuns }\end{array}$ \\
\hline - Pesquisa conjunta & - Relações públicas conjuntas \\
\hline $\begin{array}{l}\text { - Desenvolvimento conjunto de produtos e } \\
\text { processos }\end{array}$ & $\begin{array}{l}\text { - Alianças comerciais comuns } \\
\text { - Transferência de saber-fazer }\end{array}$ \\
\hline & Marketing \\
\hline \multicolumn{2}{|l|}{$\begin{array}{l}\text { - Incorporação de um produto noutro } \\
\text { - Alianças tecnológicas comuns }\end{array}$} \\
\hline \multicolumn{2}{|l|}{ Interacções de aprovisionamento } \\
\hline - Equipamentos comprados em conjunto & \\
\hline $\begin{array}{l}\text { - Aquisições conjuntas de matérias primas e } \\
\text { componentes }\end{array}$ & \\
\hline - Relações conjuntas com um fornecedor & \\
\hline
\end{tabular}

Fonte: Porter (1985).

Formular uma estratégia de uma unidade estratégica de negócio é, pelo menos, responder a estas sete questões (umas vezes em forma 
qualitativa, outras quantificando as proposições), a fim de se esboçar uma imagem da evolução esperada.

\subsection{ESTRATÉGIA DE CONJUNTO DA EMPRESA}

Antes de formular a estratégia de conjunto da empresa, deve explicitar-se o cenário de evolução da envolvente que se espera venha a acontecer. Com efeito, a imagem esperada do futuro é pertinente para a empresa, num contexto geral e numa dinâmica da envolvente que o decisor tem na cabeça.

Um cenário de evolução da envolvente expressa-se como uma história e descreve um certo número de acontecimentos deduzidos/intuídos e formulados na fase da análise prospectiva dos sistemas concorrenciais.

Um cenário é um conjunto não incoerente e simplificado de um futuro possível. Geralmente, num cenário de evolução de um sistema concorrencial encontram-se acontecimentos do tipo: taxas de crescimento da procura, evolução dos custos, movimentações dos maiores concorrentes, entrada de novos concorrentes, mudanças tecnológicas, políticas de Estados, evoluções regulamentares e sociológicas (GODET, 1985).

Imaginação, criatividade, intuição e coerência são ingredientes fundamentais na elaboração de uma estratégia de conjunto da empresa e das estratégias de negócio (HANDERSON, 1989). A intuição cruza-se com as reflexões dedutivas resultantes do diagnóstico geral de competitividade, construindo um futuro desejado e uma imagem futura da empresa.

A estratégia de conjunto da empresa engloba sete componentes de decisões ligados uns aos outros que se representa na Figura 9.

Considerar duas estratégias diferentes, cada uma delas pertinente "à priori", permite provocar os decisores e reforçar a argumentação relativa à escolha final. Algumas empresas praticam o sistema "de estratégia louca" ou de "estratégia sensata". O contraste entre as duas permite estimar os riscos da solução preferida. A escolha faz-se em função de uma breve análise das vantagens/inconvenientes (incluindo os riscos de cada estratégia relativos às incertezas mais acentuadas). 
Figura 9

COMPONENTES DA ESTRATÉGIA DE CONJUNTO DA EMPRESA

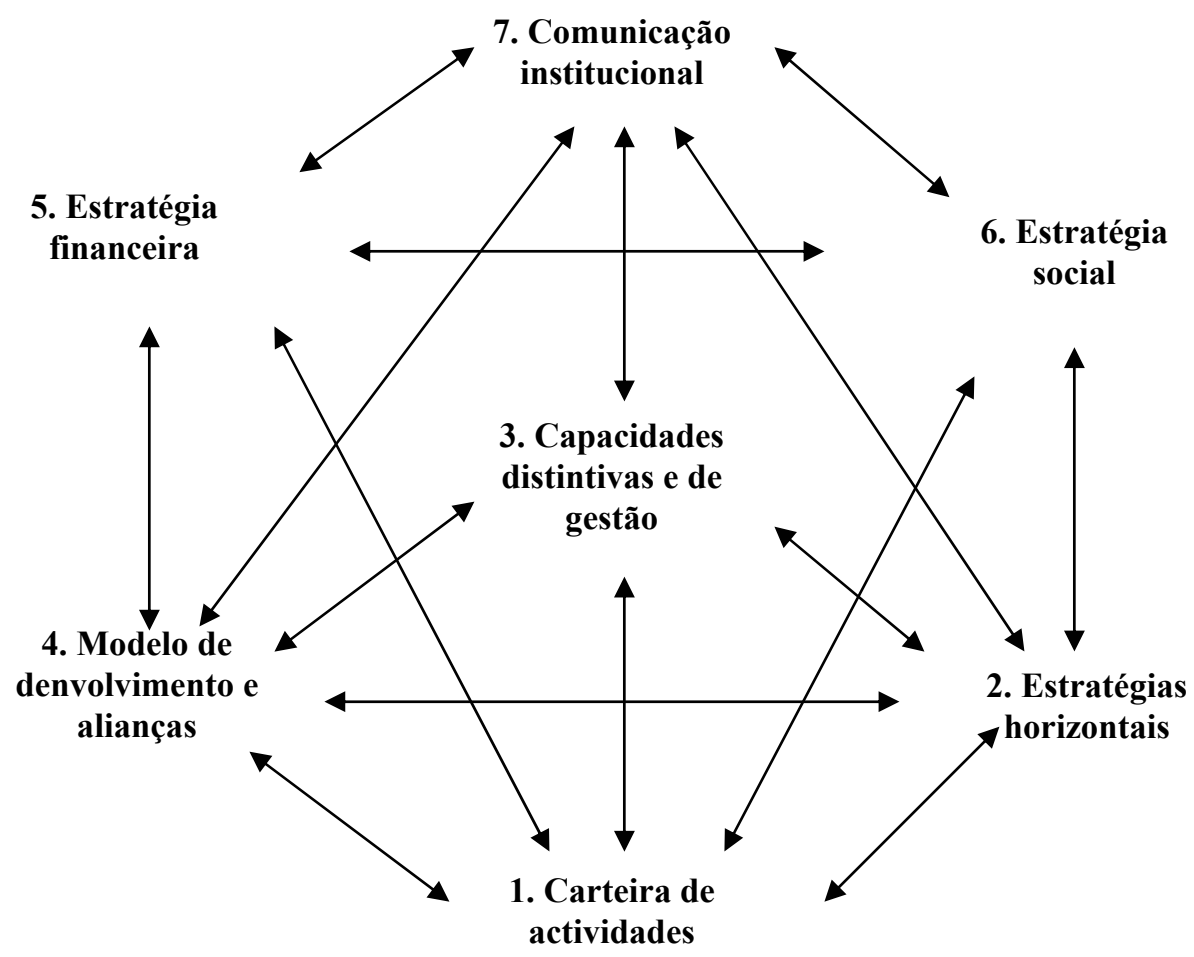

Fonte: Elaborado pela autora.

O primeiro elemento a considerar na definição da estratégia de conjunto de uma empresa é a evolução da sua carteira de actividades.

\subsubsection{Carteira de actividades da empresa}

A decisão quanto às actividades que compõem a carteira da empresa é função do diagnóstico do posicionamento estratégico da mesma, mas também do diagnóstico dos recursos, das capacidades de gestão e, por 
fim, do cenário desenhado para a envolvente, das incertezas e da finalidade da empresa.

Num primeiro nível, decidem-se eventuais movimentos de diversificação (entrada em novas unidades estratégicas de negócio ou extensões de mercado e de produto). Em contraponto, pode decidir-se uma estratégia de concentração, abandono de certas actividades estratégicas, para concentrar recursos e apontar todas as energias para as unidades estratégias seleccionadas. Enfim, o conteúdo da carteira de actividades pode ficar praticamente inalterado (nem diversificação, nem abandono).

$\mathrm{Na}$ escolha estratégica da carteira de actividades põe-se, também, o problema de afectação de recursos para investimento e exploração corrente em cada uma das unidades estratégicas de negócio. A escolha da carteira de actividades estratégicas consiste essencialmente em definir as prioridades na afectação de recursos.

\subsubsection{Estratégias horizontais}

Partilha de recursos, transferências de saber-fazer, efeitos de gama ou de imagens podem existir entre várias unidades estratégicas de negócio e tais laços conduzem à identificação das bases da estratégia.

PORTER (1986) emprega o tema estratégias horizontais e critica as grandes empresas americanas que, em nome da autonomia das suas unidades estratégicas de negócio, têm tendência a sacrificar as potenciais sinergias entre actividades, ao não seguirem uma estratégia horizontal.

Não existe um tipo padrão para expressar as estratégias horizontais, pois podem ser muito diversas. Contudo, existem alguns elementos que se devem considerar:

- acção comercial comum entre várias divisões - produtos, por intermédio de uma divisão comercial;

- acção comercial concentrada num cliente-alvo (consumindo várias linhas de produto/serviço);

- acção comercial concentrada pela entrada e desenvolvimento num mercado externo;

- uma estratégia de marca ou de comunicação institucional;

- partilha de recursos e transferências de saber-fazer em processos de produção;

- partilha de recursos e transferências de saber-fazer em métodos de gestão; 
- partilha de recursos de produção-distribuição;

- grupos de compras de matérias primas e componentes.

As estratégias horizontais formuladas cruzam as estratégias verticais das unidades estratégicas de negócio quanto a projectos cruciais para o desenvolvimento da empresa.

\subsubsection{Capacidades distintivas e de gestão}

Para além dos seus produtos e mercados e dos saber-fazer horizontais, uma empresa caracteriza-se pelas capacidades distintivas e saber-fazer de gestão. Trata-se de analisar a evolução desejada das capacidades distintivas no futuro (HIT et IRELAND, 1985).

Numa primeira observação, o diagnóstico da empresa pode evidenciar dois resultados diferentes: a) a nossa empresa não tem qualquer capacidade distintiva. b) possui uma saber-fazer duravelmente superior ao de todos os concorrentes. No primeiro caso, advém a seguinte questão: que capacidade(s) distintiva(s) queremos criar no futuro? Como?

As capacidades distintivas são uma das componentes da identidade da empresa. Trata-se, assim, de uma eventual mudança desta identidade, pelo que se torna indispensável tomar algumas precauções para evitar percursos irrealistas. No prolongamento de cada capacidade distintiva a criar, reforçar ou defender, convém colocar-se, de forma sistemática, a questão "como", até à fase de acções concretas e mensuráveis que permitam avaliar a adquabilidade da mudança.

A evolução do saber-fazer de gestão é uma componente fundamental na formulação de uma estratégia de conjunto. Podemos considerar três dimensões para analisar os saber-fazer de gestão e expressar a sua evolução:

- o tipo de sistema concorrencial em que os gestores têm experiência;

- o tipo de actividade estratégica para a qual os gestores estão preparadas;

- as funções que os gestores dominam.

Formação e recrutamento parecem ser os meios mais directos para fazer evoluir os saber-fazer de gestão. 


\subsubsection{Modelo de desenvolvimento e alianças}

As decisões quanto ao modelo de desenvolvimento: desenvolvimento interno, desenvolvimento por aquisições ou desenvolvimento partilhado tomam-se, ao nível de cada unidade estratégica de negócio, em função da situação concorrencial e das oportunidades específicas de cada negócio. No entanto, ao nível da empresa como um todo, existe geralmente uma preferência por este ou aquele tipo de desenvolvimento (HARISON, 1987).

As alianças com outras empresas, vistas como formas de desenvolvimento, são muitas vezes decididas ao nível da direcção geral, pois podem dizer respeito a várias actividades e, em todo o caso, influenciam a imagem da empresa no seu conjunto.

\subsubsection{Estratégia financeira}

As relações entre as finanças e a estratégia são ambíguas: devem limitar-se as "ambições" estratégicas de uma empresa aos seus recursos financeiros (coerência) ou devem definir-se projectos ambiciosos e, em seguida, utilizar todos os meios para mobilizar os recursos financeiros necessários (dinâmica)? Ambos os princípios nos parecem justos.

Formular uma estratégia financeira pressupõe uma estimação, mesmo que grosseira, dos recursos e empregos gerados pelo projecto estratégico. Por outro lado, alguns princípios orientadores podem ser decididos mesmo antes de qualquer avaliação.

O principal elemento de uma estratégia financeira diz respeito à repartição das fontes de financiamento da empresa (FRACHOU e ROMANET, 1985):

- quota de autofinanciamento;

- quota de empréstimos (nomeadamente a médio e longo prazo);

- quota por aumento de capital;

- política de distribuição de dividendos e de participação dos salários no capital.

As decisões sobre estratégia financeira apoiam-se num plano financeiro que, considerando o seu grau de incerteza, deve ser visto como uma simulação para testar os equilíbrios financeiros futuros. A análise dos saldos anuais resultantes de um primeiro projecto permite aferir a 
escolha das fontes de financiamento complementares, necessárias ao equilíbrio aplicações-recursos.

\subsubsection{Estratégia social}

A definição das carreiras, o desenvolvimento dos quadros, a gestão do pessoal-chave, bem como as grandes linhas do plano de formação devem ser atribuições da direcção geral da empresa, bem como a política de relações com os parceiros sociais: sindicatos e representantes dos trabalhadores. As decisões sobre política salarial, motivação do pessoal e participação dos salários no capital são geralmente harmonizadas ao nível do conjunto da empresa.

Por outro lado, entende-se por estratégia social a posição da empresa face à sua envolvente e grupos de pressão que defendem os seus interesses - envolvente social (escolas, associações) e da envolvente natural, respeito pelo equilíbrio ecológico e saúde das pessoas. Trata-se, também, da posição da empresa face às instâncias políticas — o Estado e a sua política industrial, agrícola e social.

\subsubsection{Comunicação institucional}

Para além dos produtos e serviços, as empresas comunicam acerca delas próprias, da sua identidade, ou pelo menos comunicam a imagem que desejam criar ou reforçar. A comunicação institucional pode servir para divulgar a estratégia social da empresa, ou acompanhar uma política de recursos humanos, ou ainda acompanhar uma estratégia financeira de entrada na Bolsa de Valores ou de aumento de capital. A comunicação institucional pode reforçar o anúncio de uma mudança estratégica (de carteira de actividades ou de estratégia horizontal) ou um projecto de desenvolvimento das suas capacidades distintivas.

Pode construir-se uma mensagem de comunicação institucional, tendo em conta uma das seguintes dimensões:

- as capacidades distintivas da empresa;

- a cultura da empresa, as normas de comportamento, os métodos de trabalho;

- o projecto da empresa. 
Os conteúdos destas mensagens mostram o destino de uma comunicação institucional: o grande público, certos públicos-alvo ou os trabalhadores da empresa. O objectivo é apontar o caminho, sublinhar o essencial. Para ter tal impacto, uma campanha de comunicação institucional deve assentar numa mensagem simples e utilizar meios complementares.

\section{O PROCESSO ESTRATÉGICO: QUEM, QUANDO, ONDE, COMO?}

As respostas a estas questões estão intimamente ligadas. Não se trata aqui de descrever o(s) processo(s) de tomada de decisão (vários autores, entre eles ALLISON (1969) e JOHNSON (1988) têm-no estudado), nem seguir os manuais de planeamento elaborados pelos serviços especializados das grandes empresas ou por consultores, mas o nosso objectivo é, apenas, sugerir algumas normas de conduta que devem ser consideradas ao longo de todo o processo de decisão estratégico.

\subsection{Quem?}

A questão "Quem?" é certamente a mais importante. A reflexão estratégica está reservada ao "chefe", que comunica a sua decisão aos subordinados ou, pelo contrário, é fruto de um trabalho de equipa, no qual participam vários escalões hierárquicos (processo participativo)?

Os "estrategas" são apoiados por consultores, externos ou internos?

A reflexão estratégica é conduzida em função da informação já detida pelos estrategas, ou pelo contrário, é completada por novas informações obtidas quer no interior quer no exterior da empresa (estudos de mercado, consulta a especialistas)?

Ao considerarmos estas três dimensões do processo, Figura 10, evidencia-se um afastamento significativo entre os dois extremos: a reflexão estratégica conduzida apenas pelo patrão sem informação complementar, em contraponto à reflexão estratégica conduzida pelo grupo de dirigentes e quadros superiores, assistidos por consultores e apoiando-se em novas fontes de informação.

Figura 10 


\section{ALTERNATIVAS DO PROCESSO DE FORMULAÇÃO DA ESTRATÉGIA}

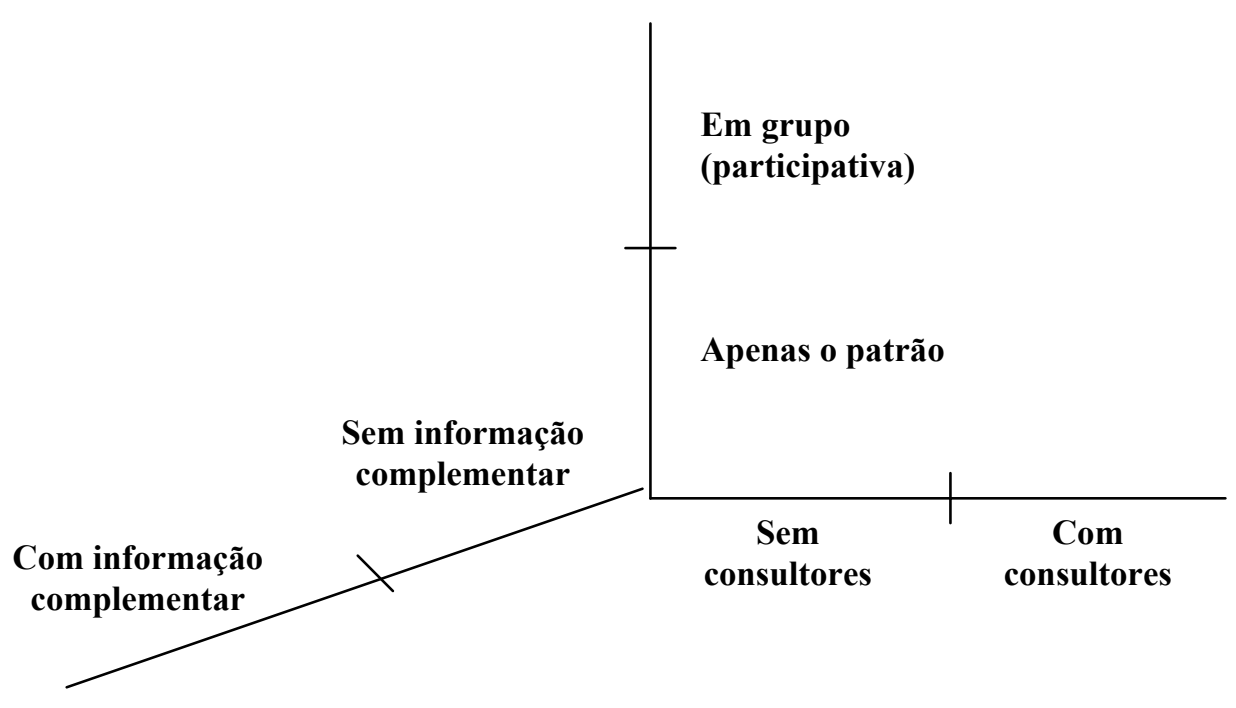

Fonte: Vencil et Lorange (1975).

A confidencialidade é porventura a maior garantia de uma reflexão ou de uma decisão preparada apenas por um único dirigente, mas o risco de existirem desvios é considerável. Neste caso, a psicologia, a experiência e os pré-julgamentos do chefe não são corrigidos pela diversidade de pontos de vista nem pela dinâmica de argumentação (criatividade). É uma das razões que nos leva a preferir um processo participativo de formulação da estratégia. A outra razão prende-se com a motivação das pessoas que participam no processo; o seu trabalho sai enriquecido através da participação nos diagnósticos e orientações, facilitando assim a passagem aos actos: a execução.

Quanto às outras duas dimensões, parece-nos preferível o recurso a consultores e informação complementar, a fim de se corrigirem os desvios de informação e apoiar a tomada de decisão. Mas estas práticas são caras, quer se trate de um consultor ou de um prestador de serviços externo, quer se trate de um consultor ou serviço especializado por avença. A solução pode passar, numa óptica de economia de recursos, por um debate em grupo sem consultores e sem recurso a informação 
complementar e, em seguida, quanto a aspectos precisos e problemas concretos, recorrer a consultores e informação complementar.

\subsection{Quando?}

A questão "quando levar a cabo uma reflexão estratégica?" deverá ter apenas uma resposta: não importa quando, desde que a inspiração e a disponibilidade permitam o emergir de ideias úteis. Os dirigentes e os quadros, todos os dias, fazem um pouco de estratégia (muitas vezes sem se darem conta). No entanto, em complemento à reflexão espontânea, põe-se a questão do ritmo mais adequado para uma reflexão colectiva e organizada.

$\mathrm{Na}$ maior parte das grandes empresas, o processo de planificação é regular e formalizado. No outro extremo, a maior parte das empresas $(\mathrm{e}$ nomeadamente as PME's) formulam uma estratégia quando surge um problema relevante: pressão sobre os preços por parte de um concorrente, entrada de novos concorrentes, inovação tecnológica, crise de tesouraria.

Para desencadear um processo de mudança e provocar a vontade de uma reflexão estratégica torna-se, muitas vezes, necessário passar por uma fase de insatisfação, isto é, passar de uma situação não desejada para uma situação desejada. As soluções curativas são muito mais utilizadas que as soluções preventivas. No entanto, nas intervenções curativas, o agravamento do problema a tratar e a necessidade de medidas rápidas reduz, geralmente, as hipóteses de sucesso (e o "medo" provoca a motivação).

\subsection{Onde?}

A resposta a esta questão está ligada à precedente; é ainda mais aberta. Pode levar-se a cabo uma reflexão estratégica: no gabinete, no metro, junto à piscina, olhando-se ao espelho, numa reunião de direcção, na cama durante uma noite de insónias, etc..

Se a reflexão é feita em grupo, os lugares propícios são mais reduzidos. Para a reflexão em grupo, a fim de permitir a troca de argumentos e uma visão global, é importante encontrar um lugar acolhedor, agradável e que rompa com os hábitos. 


\subsection{Como?}

O "como" é o objectivo principal do processo de formulação da estratégia. Neste ponto iremos fazer uma descrição genérica dos métodos de diagnóstico e formulação da estratégia, distinguindo três grandes tipos de abordagem: o "check up" da empresa, as leis universais de sucesso e os métodos de resolução de problemas.

\subsubsection{O "check up" da empresa}

O primeiro tipo de abordagem, "o check up" esteve na moda nos anos sessenta e setenta. $\mathrm{O}$ "check up" assenta numa série de questões quanto ao posicionamento da empresa, versando diversos pontos, que se deduz serem os factores de sucesso ou insucesso empresarial. Alguns gabinetes de consultores utilizam grelhas de análise organizadas por função (comercial, técnica, logística, financeira, recursos humanos, etc.) que permitem identificar os pontos fortes e fracos da empresa. As recomendações decorrem, naturalmente, das constatações feitas aquando do diagnóstico e que podem ser do tipo: a empresa concentra mais de $30 \%$ do volume de negócios num único cliente? (o perigo de dependência); se a resposta é sim, a recomendação será: diversificar os clientes e reduzir a concentração do volume de negócios no cliente em causa.

Esta forma de diagnóstico geral apenas aflora os problemas e as soluções; não estabelece qualquer ligação entre os vários elementos do diagnóstico e as propostas. Esta abordagem é, por vezes, útil para uma primeira radiografia da empresa, permitindo identificar as zonas "aparentemente" fracas e fortes da empresa.

\subsubsection{As leis universais de sucesso}

O segundo tipo de abordagem esteve na moda nos anos setenta, até ao princípio dos anos oitenta e foi baptizado por "Leis Universais de Sucesso", segundo a terminologia utilizada pelo programa PIMS (Profit Impact of Market Strategy).

A primeira vaga das leis universais de sucesso foi desencadeada pela sociedade de consultores B.C.G. (Boston Consulting Group), em 1972, com a sua teoria do efeito de experiência. Inspirada nos trabalhos de um 
economista (WRIGHT, 1925), sobre os efeitos de aprendizagem (o tempo de trabalho unitário decresce na medida em que a produção aumenta), esta teoria do efeito de experiência interessou-se por analisar a evolução dos custos unitários a longo prazo. Através de um estudo histórico da evolução dos custos unitários deflacionados nas várias indústrias, a BCG demonstrou que os custos unitários diminuíam em cerca de 10\% a 15\% cada vez que o volume de produção duplicava (BCG, 1970). A curva que relaciona estas duas variáveis é uma hipérbole (Figura 11.1), que em representação logarítmica, se transforma numa recta (Figura 11.2), cujo declive, designado efeito de experiência, traduz a percentagem de redução dos custos unitários quando se duplica o volume de produção.

Figura 11.1

RELAÇÃO CUSTO UNITÁRIO/ VOLUME DE PRODUÇÃO

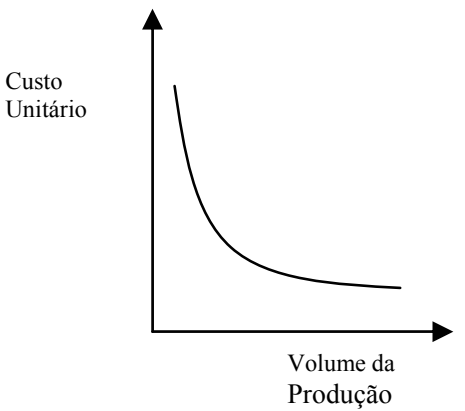

Figura 11.2 REPRESENTAÇÃO LOGARÍTMICA

Segundo esta teoria, a empresa que tivesse um maior volume de produção deveria ter custos unitários mais baixos. Tendo os custos mais baixos, a empresa líder em volume actuará sobre a política de preços: fixando os preços a um nível próximo dos seus custos, coloca em dificuldades os seus concorrentes mal posicionados em custos e precipita a sua saída do mercado; ou fixando os preços a um nível superior, permite aos concorrentes manterem-se no mercado, mas acumula lucros substanciais que podem ser distribuídos ou aplicados em novos investimentos de marketing, investigação e desenvolvimento ou em capacidade que lhe permitem melhorar o seu posicionamento. Em resumo, apenas sobreviverão numa indústria as empresas com melhor 
desempenho no que respeita ao volume de negócios ou à quota de mercado. Daí resulta a recomendação universal: estejam entre os maiores em volume de produção e conquistem quota de mercado.

Esta teoria teve um grande sucesso nos anos setenta, pois veio substituir o pensamento marketing que tinha florescido nos anos sessenta. Mas, a partir daí, a teoria tem sido alvo de vivas críticas, evidenciando os limites destas recomendações universais. Entre estas críticas, podemos realçar os seguintes pontos:

- alguns mercados são pouco ou nada sensíveis aos preços; o custo não se traduz numa vantagem competitiva determinante.

- a inovação de produtos e processos pode subverter o posicionamento em custos; a empresa líder que fez fortes investimentos numa tecnologia antiga fica enclausurada face à entrada de um concorrente inovador.

- o efeito de experiência não é automático; quando se considera o volume de produção apenas se relevam dois factores que influenciam os custos: as economias de escala e o efeito de aprendizagem; ora outros factores podem ser determinantes para criar uma vantagem em custos como, por exemplo: as inovações de produtos e processo, o grau de rotação dos activos, o custo do trabalho e do capital, a motivação dos recursos humanos e os métodos de gestão.

Finalmente, conceber uma estratégia de volume como lei universal de sucesso pode ser fatal. Contudo, ainda nos dias de hoje, algumas empresas fazem referência directa ou indirecta (recomendo a matriz de análise de carteira de negócios BCG) a esta teoria, apesar de ultrapassada.

Foram os resultados da base de dados PIMS que relegaram para segundo plano a teoria do efeito de experiência.

Desde 1974 que o "Strategic Planning Institute" recolhe informação sobre o posicionamento e movimentos estratégicos e o desemprenho financeiro de empresas inscritas numa base de dados designada PIMS. Passados estes anos, cerca de 3000 unidades estratégicas de negócio são estudadas neste programa, pertencendo estas unidades estratégicas às grandes empresas americanas e algumas europeias. Desde os finais dos anos setenta que o PIMS proclama as suas nove "Leis Universais de Sucesso", nove factores que explicam $80 \%$ das variações da rentabilidade dos investimentos (BUZZELL et GALE, 1987). Sem entrar em detalhes, apresentam-se os nove factores por ordem de importância: 
- Intensidade de Capital: medido pela relação Investimento/ /Volume de negócios anual; a intensidade de capital está negativamente ligada à rentabilidade dos investimentos, pelo que para aumentar a rentabilidade torna-se necessário utilizar em pleno o aparelho produtivo, reduzir "stocks", melhorar a flexibilidade face às flutuações conjunturais através da sub-contratação e tecnologias flexíveis.

- Produtividade do Trabalho: medida pela relação valor acrescentado/número de efectivos; a produtividade do trabalho está positivamente relacionada com a rentabilidade dos investimentos. Existem ganhos de rentabilidade com a melhoria da produtividade do trabalho, quer pela inovação tecnológica, quer pela motivação e mudança de comportamentos.

- Crescimento do Mercado: medido pela taxa de crescimento do mercado em volume; a taxa de crescimento do mercado está positivamente relacionada com a rentabilidade dos investimentos. Em mercados com forte crescimento, cada concorrente pode crescer sem necessariamente o fazer em detrimento do crescimento dos outros, pelo que as guerras de preços e as retaliações desesperadas são mais raras. Em consequência, devem escolher-se segmentos com maiores taxas de crescimento.

- Posicionamento no mercado: medido pela quota relativa do mercado (quota de mercado da empresa sobre as quotas de mercado dos três maiores concorrentes). Provavelmente, graças às economias de escala (em marketing, investigação e desenvolvimento e produção), as empresas-líder são as mais rentáveis. Refira-se que este factor apenas aparece em quarto lugar para explicar a rentabilidade, embora para o BCG constituísse a Lei Universal de Sucesso.

- Posicionamento na qualidade: medido por um índice composto por vários critérios que traduzem as preferências dos clientes em comparação com o melhor concorrente. Um posicionamento superior em qualidade está positivamente relacionado com a rentabilidade dos investimentos.

A combinação destes dois factores, elevada quota de mercado relativa e elevado posicionamento em qualidade é possível e tem dado resultados excepcionais quanto à rentabilidade (BUZZEL et GALE, 1987).

- Os esforços de inovação e diferenciação: medido pelo nível relativo dos investimentos em marketing e investigação e 
desenvolvimento (em percentagem sobre o volume de negócios). $\mathrm{O}$ impacto sobre a rentabilidade depende da posição que a empresa tem no mercado. Se a quota de mercado é elevada, o impacto dos esforços de inovação e diferenciação é positivo; pelo contrário, se a posição no mercado é fraca, o impacto é negativo. Noutros termos, provavelmente é necessário ter em atenção que a inovaçãodiferenciação traduz-se num ganho substancial de quota de mercado antes de colher os proveitos sobre a rentabilidade.

- A integração vertical: estimada por um índice que traduz o número de funções ocupadas pela empresa na cadeia vertical de concepção-produção-distribuição em relação ao máximo possível. $\mathrm{O}$ impacto sobre a rentabilidade depende da turbulência do sistema concorrencial. Se a actividade é madura e estável, uma forte integração vertical está relacionada com um efeito positivo na rentabilidade; se a actividade é emergente e instável, uma fraca integração vertical está ligada a uma elevada rentabilidade. A explicação deste fenómeno pode estar ligada à maior flexibilidade de uma empresa com estratégia de focalização, própria de um mercado turbulento e aos elevados custos de transaç̧ão, próprios de um mercado maduro.

- A pressão sobre os custos: medida pela pressão fiscal e pressão sobre os salários. Este factor aparece em oitavo lugar para explicar a rentabilidade, o sentido é evidente: fortes pressões resultam em fracas rentabilidades. Se a base de dados PIMS contemplasse mais empresas implantadas em paraísos fiscais ou em países com baixos custos salariais, este factor podia ter mais importância.

- A fase da implementação da estratégia: a curto prazo, um movimento estratégico para melhorar o posicionamento da empresa (ganhos de quota de mercado, esforços na qualidade e diferenciação) traduz-se, geralmente, num efeito inverso ao efeito sobre a rentabilidade. Apenas a médio/longo prazo (variável), o efeito sobre a rentabilidade se torna favorável.

Os resultados do PIMS interessaram vivamente aos dirigentes das grandes empresas. Mas a sua utilização está limitada ao delineamento de um painel de gestão, composto por uma vintena de indicadores derivados das leis universais de sucesso.

A terceira vaga das leis universais de sucesso foi concebida por PETERS e WATERMAN (1982) que, na sua obra "O Preço da Excelência", propuseram as suas oito leis universais de sucesso. O estudo 
de trinta e seis grandes empresas americanas que obtiveram um excelente desempenho económico e financeiro (crescimento e inovação) está na base destas regras:

- antecipar a acção;

- ter em atenção o cliente;

- fomentar a autonomia e o espírito da empresa;

- assentar a produtividade na motivação dos recursos humanos;

- mobilizar-se à volta de valores partilhados;

- agarrar-se aquilo que se sabe fazer;

- preservar uma estrutura simples e ligeira;

- conciliar flexibilidade e rigor.

As respostas universais de PETER et WATERMAN são, contudo, diferentes das respostas do PIMS. Estas diferenças explicam-se, em parte, pelo facto do Strategic Planning Institute trabalhar ao nível de unidades estratégicas de negócios sobre variáveis técnico-económicas, enquanto PETER e WATERMAN trabalharam ao nível do conjunto da empresa sobre variáveis principalmente organizacionais e culturais.

Em resumo: as receitas universais de sucesso seduzem pelas suas provas estatísticas (mais ou menos sólidas) e pela sua simplicidade que contrasta com a complexidade da gestão quotidiana da empresa. É preciso ser prudente nas suas conclusões e conhecer os limites da sua utilização.

\subsubsection{Os métodos de Resolução dos Problemas Estratégicos}

Existe na literatura sobre estratégia, desde ANSOFF a MINTZBERG, referência a um conjunto de métodos de técnicas de resolução dos problemas estratégicos, atendendo às características particulares de uma situação concreta; mais vale saber como encontrar e resolver os problemas do que crer em receitas de sucesso.

Iremos, de seguida, descrever as principais etapas do processo de reflexão estratégica, fazendo referência a alguns métodos utilizados e evidenciados na vasta literatura sobre estratégia.

Toda a reflexão estratégica assenta em:

\section{A) Diagnóstico geral}

\section{- O diagnóstico do posicionamento estratégico}

1. Análise da empresa quanto à sua individualidade, à sua "identidade" (política geral actual, valores, sistema de gestão e 
orientação estratégica) e à sua "diversidade" (segmentação estratégica do conjunto das suas actividades que permita identificar as unidades estratégicas de negócio, os seus factores chave de sucesso e a partilha de recursos e capacidades).

2. A análise dos sistemas concorrenciais nos quais a empresa está envolvida: segmentação da indústria, tipo de indústria, análise das forças competitivas e análise prospectiva de cada sistema concorrencial permitem avaliar a criação de valor de cada actividade, as oportunidades e ameaças.

3. A análise do posicionamento competitivo da empresa em cada sistema concorrencial face aos factores chave de sucesso ou fontes de criação de valor, a análise do conjunto das posições estratégicas da empresa ou análise da carteira de actividades, atractividade das indústrias e posicionamento competitivo.

\section{- O diagnóstico dos recursos}

Tem por objectivo avaliar os saber-fazer "transversais", os recursos humanos, tecnológicos e financeiros e explicar as eventuais deficiências ou problemas.

\section{- O diagnóstico das capacidades de gestão}

Engloba o diagnóstico da organização (sistema de informação, sistema de poder e estrutura) e o diagnóstico do estilo de gestão e da cultura da empresa.

\section{- A síntese do diagnóstico}

É uma fase crucial para preparar a comunicação dos resultados e para estimular a intuição futura dos estrategas. Assenta na definição do problema e identificação dos domínios de excelência.

$\mathrm{Na}$ prática, o diagnóstico estratégico representa dois terços do caminho. No limite, se faltar tempo, uma reflexão estratégica participada reduzida ao diagnóstico seria útil por ela mesma, pois os quadros que participaram, retomariam os seus afazeres quotidianos conscientes dos pontos a melhorar e, na sequência das acções, uma estratégia emergiria progressivamente.

\section{B) Formulação da estratégia}

- Numa primeira fase da formulação da estratégia, explicitam-se os cenários de evolução da envolvente, evidenciam-se as 
incertezas mais relevantes e definem-se as missões da empresa bem como a estratégia de conjunto.

- Numa segunda fase, elabora-se a estratégia para cada unidade estratégica de negócio: grau de envolvimento, metas, vantagens competitivas, tecnologias, posicionamento na cadeia vertical, modelo de desenvolvimento e alianças específicas, interrelações com as outras actividades.

- Por fim, a reflexão estratégica tem por objectivo a procura de coerência entre a evolução dos recursos, da organização e da cultura da empresa e as orientações estratégicas. As mudanças mais significativas são objecto de um "plano de acções prioritárias" a curto prazo e traduzidas num "plano de desenvolvimento dos recursos humanos". Torna-se necessário preparar um sistema de vigilância que permita perceber as mudanças mais significativas na envolvente e medir os progressos da empresa quanto às acções prioritárias .

A avaliação dos planos de acções prioritárias e do plano de desenvolvimento dos recursos humanos arrasta consigo, muitas vezes, a necessidade de revisão do primeiro desenho estratégico. Geralmente, é necessário o recurso a interacções sistemáticas para precisar ou retocar as decisões.

O processo aqui proposto pretende-se que seja racional, contudo, a maior parte das vezes, as decisões estratégicas não seguem um tal processo; fenómenos políticos e culturais enviesam as análises e as propostas. Torna-se assim fundamental compreender os fenómenos políticos e culturais para reparar os desvios mais significativos e saber interpretá-los.

\section{NOTAS}

* Texto da Lição Síntese apresentada nas Provas de Agregação, área científica de Economia Agrária - Gestão de Empresas, na Universidade de Trás-os-Montes e Alto Douro. 


\section{BIBLIOGRAFIA}

ABELL, D. F. (1979), Defining the Business, Prentice Hall, Englewood Cliffs.

ALlisON, G. T. (1969), "Conceptual Models", American Political Science Review, September.

ALlisON, G. T. (1969), Conceptual Models, American Political Science Review, Septembre.

ANSOFF, H. I. (1974), Strategie du Développement de l'Entreprise, Hommes et Techniques.

ATAMER, T. et al. (1988), "The Impact of External Consultancy on Strategic Change Within Small and Medium Sized French Campanies", Cahiers de recherche de l'I.G.R., IAE de Rennes.

BOSTON CONSULTING GROUP (1970), Perspectives on Experience, B.C.G., Boston.

BOYER, L. et EQUILBEY, N. (1990), Histoire $d u$ Management, Editions d'Organisation.

BUZZELL, R. D. et GALE, B. T. (1987), The PIMS Principles, Linking Strategy to Performance, The Free Press, New York.

CALORI, R. (1989), "Stratégie: Sayons Réalistes", Harvard - L'Expansion, $\mathrm{n}^{\circ}$ 52, Printemps.

CALORI, R. et ATAMER, T. (1989), L'Action Stratégique: Le Management Trnsformateur, Les Éditions d'Organisation.

FRACHON, G. et ROMANET, Y. (1985), Finance d'Entreprise: Comprendre et Maitriser l'évolution Financière de l'Entreprine, CLET.

FREIRE, A. (1998), Estratégia. Sucesso em Portugal, Editorial Verbo, Lisboa

GODET, M. (1985), "Prospective et Planification Stratégique", Economica.

GONOD, P. (1996), "Dynamique des systèmes et méthodes prospectives", Travaux et Recherches de Prospective, $\mathrm{n}^{\circ} 2$.

HENDERSON, B. (1989), "The Origin of Strategy", Harvard Business Review, November-December.

HITT, M. A. et IRELAND, R. D. (1987), "Peters and Waterman Revisited", Academy of Management Executive, vol. 1, $\mathrm{n}^{\mathrm{o}} 2$.

JOHNSON, G. (1988), "Rethinking Incrementalism", Strategic Management Journal, Vol. 9, nº 1, Janvier-Féverier.

KOTLER, J. (1990), Le leadership: le de l'avantage concurrentiel, Inter Éditions.

LE SAGET, M. (1992), Le manager intuitif, Dunod.

LEVITT, T. (1991), Réflexions sur le management, Dunod. 
MINTZBERG, H. et WATERS, J. A. (1985), "Of Strategies, Deliberate and Emergent", Strategic Management Journal, vol. 6, $\mathrm{n}^{\circ}$ 3, Primavera.

PASCALE, R. T. (1984), "Perspectives on Strategy: The Real Story Behind Honda's Success", California Management Review, Vol. 26, nº 3.

PETERS, T. et WATERMAN, R. (1983), Le Prix de l'Excellence. Inter Éditions (Versão americana, Harper and Row, 1982).

PORTER, M. (1985), Competitive Advantage, The Free Press, New York.

SANTOS, F. (1998), Estratégia e competitividade, Centro de Informação, Formação e Aperfeiçoamento em Gestão, Rei dos Livros, Lisboa

SCHWARTZ, P. (1993), "La planification stratégique par scénarios", Futuribles, $\mathrm{n}^{\mathrm{o}} 176$.

SICARD, C. (1995), "Élaborer des stratégies gagnantes", Management France, $\mathrm{n}^{\circ} 93$.

TICHY N. M. (1983), Managing Strategic Change, Wiley Interscience, New York.

VENCIL, R. F. et LORANGE, P. (1975), "Strategic Planning in Diversified Companies", Harvard Business Review, Janeiro-Fevereiro. 